\title{
Insensibilidad congénita al dolor con anhidrosis. Diagnóstico clínico, evolución y complicaciones. Reporte de un caso
}

\author{
Congenital insensitivity to pain with anhidrosis. Clinical diagnosis, evolution \\ and complications. Case report
}

\author{
Dr. Byron Orlando Albuja Echeverría ${ }^{a}$ Dra. Mayra Bersabeth Alvear Lozano ${ }^{a}$ \\ Dra. Carla Patricia Ordóñez Paredes ${ }^{a}$
}

\begin{abstract}
RESUMEN
La insensibilidad congénita al dolor con anhidrosis es una enfermedad autosómica recesiva infrecuente, que se produce por mutaciones en el gen NTRK1 (neurotrophic tyrosine receptor kinase 1), localizado en el cromosoma 1q21-22, que codifica el dominio tirosinasa del receptor de alta afinidad del factor de crecimiento nervioso. Se caracteriza por anhidrosis, insensibilidad a los estímulos dolorosos y retraso mental.

Dada su baja prevalencia y los pocos casos reportados, es importante conocer sus principales características para considerarlo entre los diagnósticos diferenciales en la práctica pediátrica.

Realizamos la descripción del diagnóstico clínico, complicaciones, secuelas y tratamiento sintomático administrado en una niña de 3 años y 6 meses en el Hospital Asdrúbal de la Torre, Cotacachi, Ecuador.

Palabras clave: congénito, insensibilidad, dolor, anhidrosis.
\end{abstract}

\section{ABSTRACT}

The congenital insensitivity to pain with anhidrosis is a rare autosomal recessive disease caused by mutations in NTRK1 gene (neurotrophic tyrosine kinase receptor 1) located in chromosome 1q21-22, encoding the tyrosinase domain receptor high affinity nerve growth factor. It is characterized by anhidrosis, insensitivity to painful stimuli and mental retardation.

Given their low prevalence and the few reported cases, it is important to know its main features to be considered in the differential diagnosis in pediatric practice.

We describe the clinical diagnosis, complications, sequelae and symptomatic treatment administered to a 3 years and 6 months old girl in the Hospital Asdrubal de la Torre, Cotacachi, Ecuador. Key words: congenital, sensory loss, pain, anhidrosis.

http:/ /dx.doi.org/10.5546/aap.2014.e200

a. Hospital Asdrúbal de la Torre. Cotacachi, Ecuador.

Correspondencia:

Dr. Byron Orlando Albuja Echeverría: byoral3@gmail.com

Conflicto de intereses: ninguno que declarar.

Recibido: 29-11-2013

Aceptado: 9-4-2014

\section{INTRODUCCIÓN}

El dolor es una experiencia común al ser humano y cumple una función protectora. Las enfermedades que cursan con la ausencia de la percepción dolorosa llevan a múltiples problemas para los afectados, que, en ocasiones, pueden poner en riesgo su vida. ${ }^{1-2}$

A nivel mundial, existen pocos casos de insensibilidad congénita al dolor con anhidrosis (CIPA); es uno de los trastornos autosómicos recesivos más raros. Este es el primer caso diagnosticado en el Hospital Asdrúbal de la Torre de Cotacachi y no hemos encontrado otros casos registrados en el Ecuador.

La CIPA o neuropatía autonómica y sensorial hereditaria tipo IV (HSAN tipo IV) está caracterizada por anhidrosis, insensibilidad a los estímulos dolorosos y retraso mental. ${ }^{2-4}$

Las patologías relacionadas con la insensibilidad congénita al dolor fueron descritas por Dearborn en 1931. Dyck (1984) clasificó las HSAN en cinco tipos ${ }^{4}$ (Tabla 1).

\section{CASO CLÍNICO}

Presentamos el diagnóstico clínico, complicaciones, secuelas y tratamiento sintomático administrado en una niña de 3 años y 6 meses en el Hospital Asdrúbal de la Torre, Cotacachi, Ecuador.

\section{Antecedentes familiares}

La hermana fallece a los 18 días de vida sin diagnóstico establecido; el tío abuelo materno presenta retraso mental.

\section{Evolución}

Paciente de etnia indígena, producto de la tercera gestación, parto atendido en domicilio (llanto inmediato), recién nacida a término con antropometría normal. A las 72 horas de vida, presentó fiebre, por lo que fue ingresada a un centro hospitalario, en donde permaneció por 26 
días y fue dada de alta sin diagnóstico específico. A partir del mes de edad, presentó episodios recurrentes de fiebre sin foco determinado.

A los 4 meses, fue diagnosticada con neumonía. Durante la hospitalización, llamó la atención la ausencia de respuestas a estímulos dolorosos durante la colocación del acceso venoso. Al momento del examen físico, se observó la presencia de una lesión dérmica ulcerosa de $1 \mathrm{~cm}$, de bordes regulares en la falange proximal y distal del primer dedo de la mano derecha, y lesiones en proceso de cicatrización en el segundo dedo (Figura 1). La evaluación neurológica mostró hipotonía generalizada, movimientos simétricos activos, sostén cefálico incompleto, ausencia de respuesta a estímulos dolorosos y térmicos en todo el cuerpo, reflejos tendinosos profundos normales, reflejo corneal ausente. Bajo anestesia general, se realizó una biopsia de piel de la región esternal. El informe mostró

TABLA 1. Neuropatías hereditarias sensitivo-autonómicas (HSAN): cuadro comparativo

\begin{tabular}{|c|c|c|c|c|c|}
\hline Característica & HSAN tipo I & HSAN tipo II & $\begin{array}{c}\text { HSAN tipo III } \\
\text { Disautonomía familiar/ } \\
\text { síndrome de Riley Day }\end{array}$ & $\begin{array}{c}\text { HSAN tipo IV } \\
\text { Insensibilidad congénita } \\
\text { al dolor con anhidrosis }\end{array}$ & HSAN tipo $\mathrm{V}$ \\
\hline Herencia & $\mathrm{AD}-\mathrm{AR}$ & $\mathrm{AR}$ & $\mathrm{AR}$ & $\mathrm{AR}$ & $\mathrm{AR}$ \\
\hline $\begin{array}{l}\text { Edad de } \\
\text { aparecimiento }\end{array}$ & $2^{\text {da }}$ década de vida & Infancia & Nacimiento & Nacimiento & Nacimiento \\
\hline $\begin{array}{l}\text { Insensibilidad } \\
\text { al dolor }\end{array}$ & ++ & ++ & + & +++ & ++ \\
\hline Hidrosis & Normal & Normal & Disminuida & Disminuida o ausente & Normal \\
\hline Retardo mental & Ausente & $-/+$ & + & + & $+/-$ \\
\hline Hipotonía muscular & Ausente & Ausente & + & + & Ausente \\
\hline $\begin{array}{l}\text { Reflejos tendinosos } \\
\text { profundos }\end{array}$ & Ausente & Ausente & A menudo o ausente & Normal o disminuido & Normal \\
\hline $\begin{array}{l}\text { Velocidad de } \\
\text { conducción } \\
\text { nervioso-motor }\end{array}$ & Variable & $\begin{array}{l}\text { Medianamente } \\
\text { enlentecido }\end{array}$ & $\begin{array}{l}\text { Normal o } \\
\text { deprimido }\end{array}$ & $\begin{array}{l}\text { Normal o } \\
\text { deprimido }\end{array}$ & Normal \\
\hline $\begin{array}{l}\text { Velocidad de } \\
\text { conducción } \\
\text { nervioso-sensorial }\end{array}$ & $\begin{array}{l}\text { Disminuido o } \\
\text { ausente }\end{array}$ & $\begin{array}{l}\text { Disminuido o } \\
\text { ausente }\end{array}$ & $\begin{array}{l}\text { Disminuido o } \\
\text { ausente }\end{array}$ & $\begin{array}{l}\text { Disminuido o } \\
\text { ausente }\end{array}$ & Normal \\
\hline $\begin{array}{l}\text { Hallazgos en } \\
\text { biopsia }\end{array}$ & $\begin{array}{l}\text { Disminución } \\
\text { de FA y FM }\end{array}$ & FM ausente & Reducción FA & Ausencia FA & $\begin{array}{l}\text { Ausencia de } \\
\text { FM pequeñas }\end{array}$ \\
\hline
\end{tabular}

HSAN: neuropatía autonómica y sensorial hereditaria. AD: autosómico dominante. AR: autosómico recesivo.

FA: fibras amielínicas. FM: fibras mielínicas.

Fuente: Mobini M, Javadzadeh A, Forghanizadeh J. Neuropathic osteroarthropathy in a patient with congenital insensivity to pain. Arch Iran Med 2009;12(6):599-602.

FIGURA 1. Lesión dérmica ulcerosa y lesiones en proceso de cicatrización producidas por automutilación
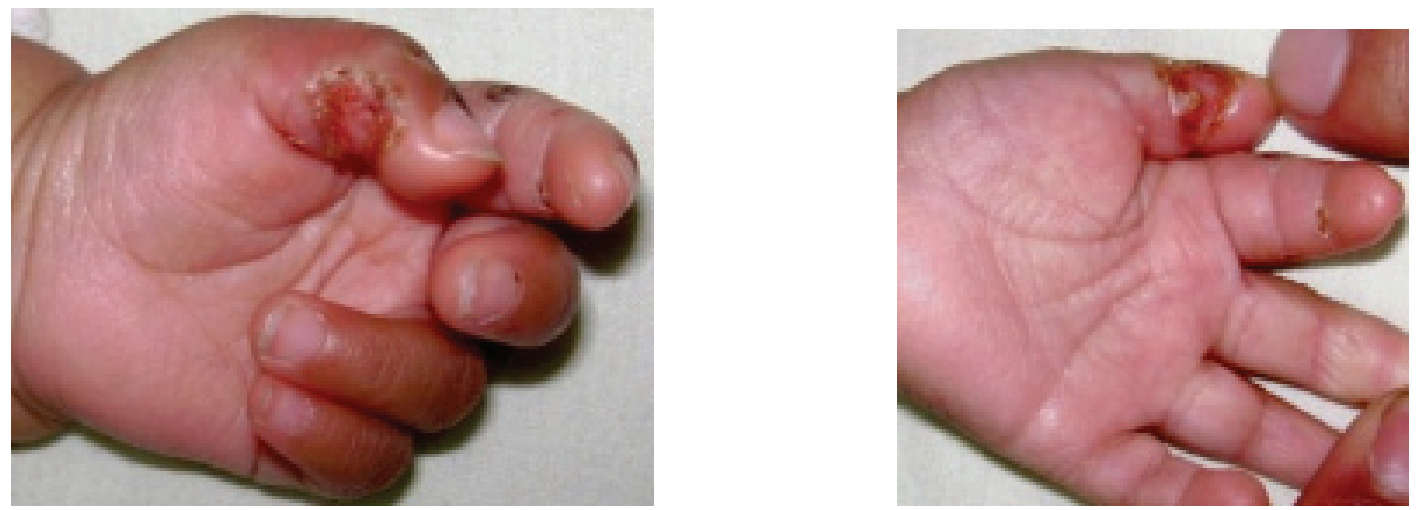
dermis superficial y profunda con algunos anexos cutáneos constituidos por folículos pilosos y glándulas sudoríparas, que, en múltiples cortes, no presentaban zonas de inervación adjuntas. Tinción de inmunohistoquímica para fibras nerviosas: proteína S100, negativa (Figura 2).

A los 9 meses, presentó un nuevo cuadro de fiebre intermitente de hasta $39,2^{\circ} \mathrm{C}$ por tres días, producida por enfermedad diarreica aguda. No presentó convulsiones febriles.

A los 16 meses, presentó placas ulcerosas en la mucosa oral, enfermedad de Riga-Fade (Figura 3.a), y se diagnosticó osteomielitis de las falanges distales del primer y segundo dedo de la mano izquierda (cultivo positivo para Staphylococcus aureus sensible a la cefalexina). A

FIguRa 2. Placa de piel: de abajo hacia arriba, se observa la epidermis delgada, fina con un poco de hiperqueratosis; hacia arriba, se observan pocos anexos, un folículo piloso y escasas glándulas sebáceas. Con el aumento, se observa de cerca el folículo piloso y las glándulas sebáceas; en toda la placa, no se observan filetes de terminaciones nerviosas

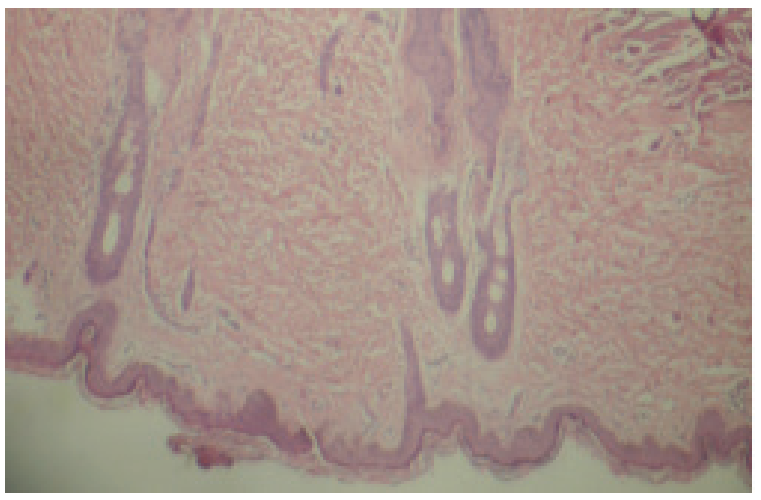

los 17 meses, presentó deformidad de la lengua (Figura 3.b). En dos procedimientos diferentes y bajo anestesia general, se realizó la exodoncia de dientes diciduos (incisivos: 51, 52, 61, 62; caninos: $53,63,73$ y 83$)$.

A los 25 meses, tuvo un nuevo episodio de fiebre intermitente de hasta $38,8^{\circ} \mathrm{C}$ por 3 días, secundario a una infección de las vías urinarias (cultivo positivo para Escherichia coli sensible a la amoxicilina con ácido clavulánico).

A los 30 meses y, posteriormente, a los 38 meses, presentó úlceras corneales bilaterales de origen traumático (con respuesta favorable al tratamiento antibiótico y lubricación).

A los 40 meses, se detectó una úlcera de $0,5 \mathrm{~cm}$, redonda y de bordes regulares en la palma izquierda, aparentemente producida por el gateo; se acompañó de deformidad ósea de los dedos de las manos (Figura 4).

\section{Evolución antropométrica:}

- Peso y talla: hasta los 6 meses de edad, permaneció sobre -2 DE. Desde los 6 a 12 meses, se observó una curva plana. A partir de los 12 meses, permaneció por debajo de $-3 \mathrm{DE}$.

- Perímetro cefálico: hasta los 3 meses de edad, permaneció sobre -2 DE. Desde los 3 a los 6 meses, se observó una curva plana. A partir de los 6 meses, permaneció por debajo de -2 DE.

El desarrollo psicomotor se evaluó a través del test de Denver, en el que se evidenció un retraso madurativo global. En relación con los exámenes complementarios de laboratorio e imágenes relevantes, cabe señalar función tiroidea normal, fondo de ojo normal, TAC de cráneo normal (estudios realizados durante el primer año de vida).
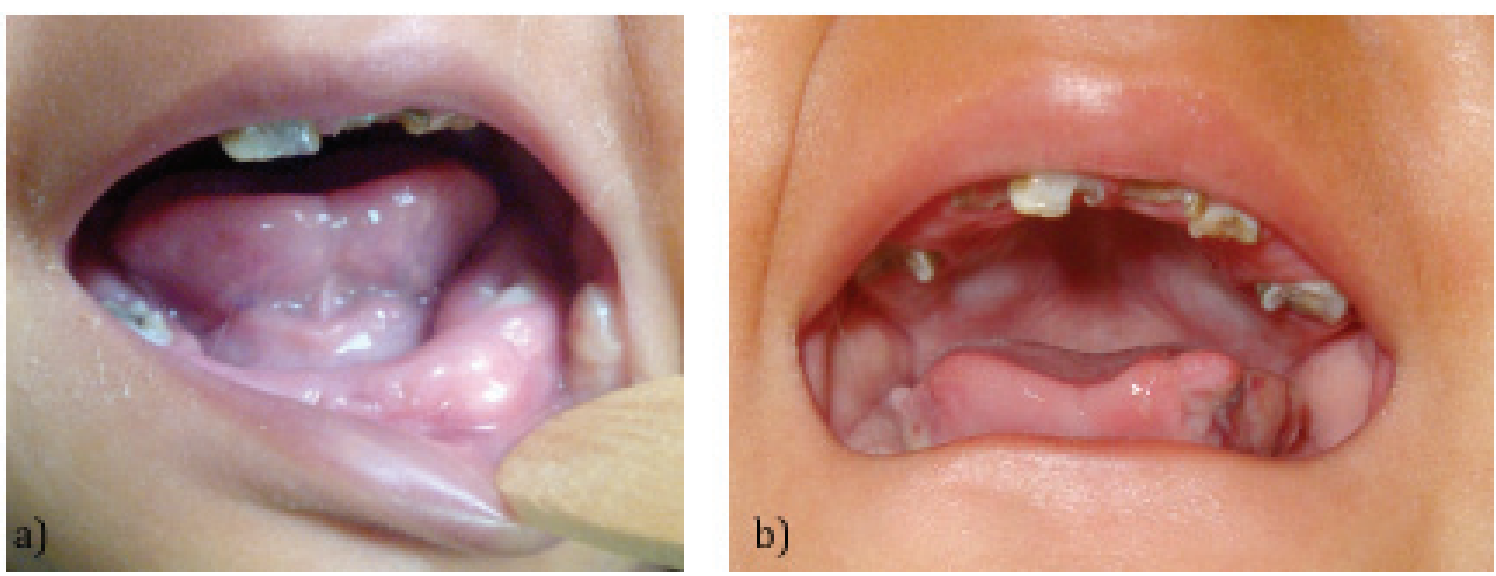


\section{DISCUSIÓN}

La insensibilidad congénita al dolor con anhidrosis se origina por una mutación en el gen receptor neurotrófico tirosinasa 1 (NTRK1), que está localizado en el cromosoma 1q21-22, que codifica el dominio tirosinasa del receptor de alta afinidad del factor de crecimiento nervioso. Esta alteración génica determina el fracaso de la diferenciación y migración de las células de la cresta neural y, en consecuencia, la ausencia completa de fibras mielinizadas pequeñas y no mielinizadas encargadas de la percepción del dolor y la temperatura, así como la ausencia de inervación de las glándulas sudoríparas. ${ }^{2,5-7}$

El principal estudio que confirma la presencia de esta patología es la detección de la mutación en NTRK1, que se identifica mediante secuenciación genética, ${ }^{8,9}$ pero, al ser este un estudio de difícil acceso en nuestro país, no se realizó. En el caso descrito, existe una fuerte sospecha clínica por la sumatoria de criterios y por los resultados de la biopsia de piel.

En el caso presentado, aparentemente, no existe consanguinidad entre los padres, pero es importante señalar que los progenitores comparten un apellido y son oriundos de la misma comunidad indígena (posible endogamia), lo que explicaría un mayor riesgo de trastornos hereditarios autosómicos recesivos en su descendencia.

El primer signo de este síndrome es la fiebre secundaria a la anhidrosis, la cual tiene presentación recurrente desde el período neonatal o desde los primeros meses de vida. ${ }^{2-7-10}$ Debido a la poca frecuencia de este desorden y a la ausencia de otros signos que orienten a su diagnóstico, inicialmente, se describen los episodios febriles recurrentes, como fiebre de origen por determinar. Las convulsiones febriles se presentan con frecuencia y se describe que el $20 \%$ de los casos de muerte en los tres primeros años de vida son producidos por hiperpirexia. ${ }^{2,3,7,10}$

La educación continua a la madre y sus familiares en el control de la temperatura ha sido vital para el manejo de nuestra paciente. Los episodios febriles con temperatura mayor de $38,5^{\circ} \mathrm{C}$ se han podido controlar con medios físicos y la administración de paracetamol en dosis terapéutica de $15 \mathrm{mg} / \mathrm{kg}$ cada 6 horas. Por lo general, los episodios de fiebre mayor de $38,5^{\circ} \mathrm{C}$ se han asociado a infecciones y no han sido necesarios períodos prolongados de administración de paracetamol (generalmente, se administró de 2 a 3 días) y no se requirieron otros medicamentos.

FIGURA 4. Úlcera en la palma izquierda, secundaria a lesión traumática por gateo, múltiples lesiones en proceso de cicatrización y deformidad ósea de los dedos de las manos

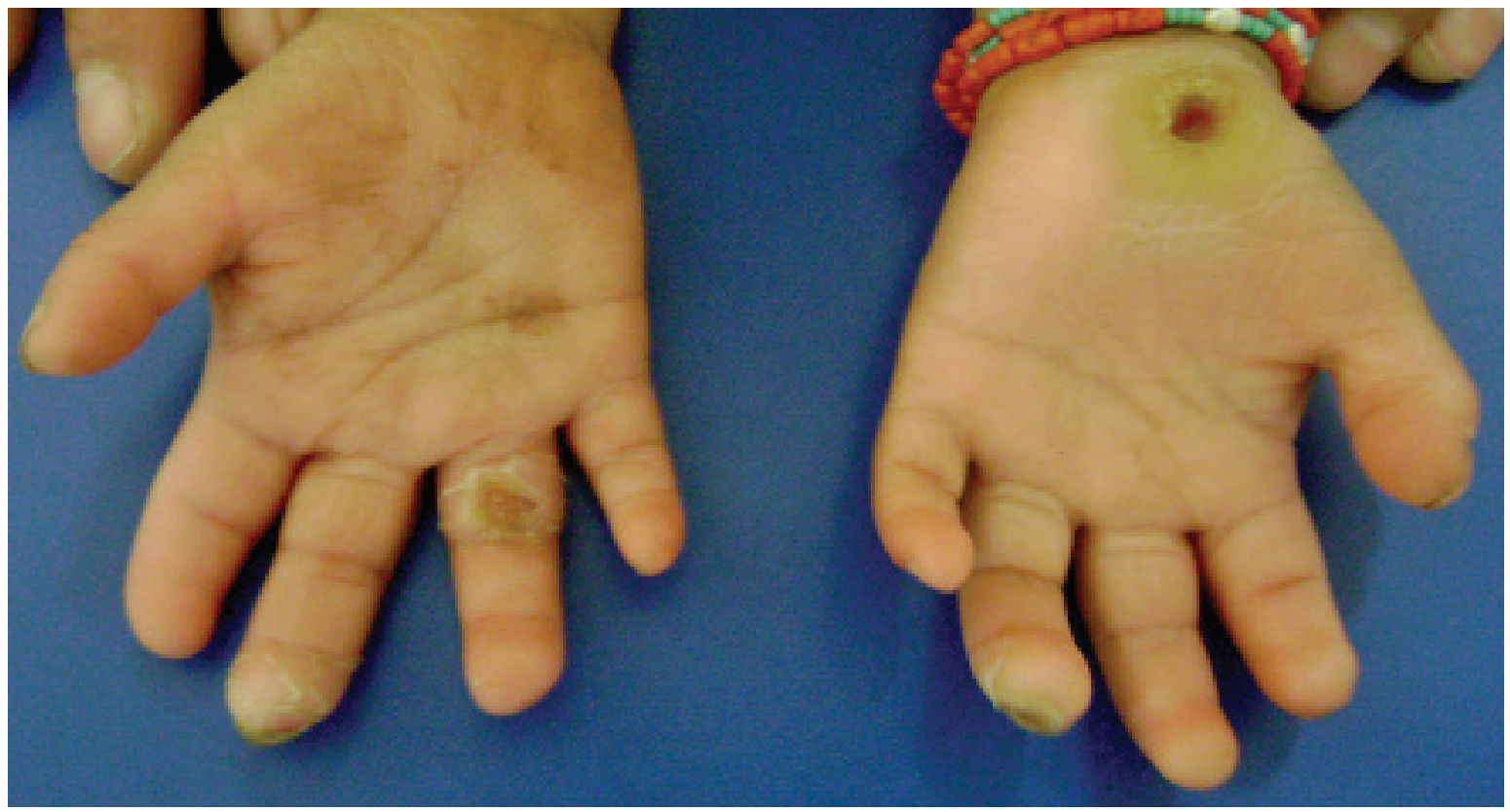


Como consecuencia de la ausencia de sensibilidad dolorosa y térmica, se producen lesiones en distintos niveles. Son comunes las alteraciones de la piel (laceraciones, úlceras, infecciones, quemaduras) y ortopédicas (fracturas múltiples con formación de hueso hiperplásico, que afecta fémur y tibia; articulaciones de Charcot; dismetría de extremidades inferiores; escoliosis progresiva; osteomielitis; artritis sépticas; luxaciones; amputaciones y automutilaciones)., ${ }^{2,11}$

En el caso presentado, la aparición de la dentición antes de los 4 meses de edad fue un factor desencadenante de lesiones de automutilación, que originó desde la presencia de lesiones menores hasta úlceras e infecciones graves, como osteomielitis. La respuesta al tratamiento antibiótico fue favorable y se evitó la amputación de las falanges. La niña presenta deformidad de los dedos de las manos como secuela.

El resultado de traumas repetitivos en la mucosa oral (enfermedad de Riga-Fade), lesiones ulcerosas y posterior deformidad de la lengua, sumados a las complicaciones de la piel y las complicaciones ortopédicas fueron controladas mediante la exodoncia de dientes deciduos. Se presentó falta de desarrollo maxilar y mandibular como secuela.

La lesión oftalmológica más frecuente de la HSAN tipo IV y secundaria a la ausencia de sensibilidad corneal es la úlcera, que suele tener una evolución tórpida. Se debe hacer un diagnóstico diferencial con las queratitis neurotróficas. ${ }^{2,11}$ En el caso, se describe la presencia de esta complicación por dos ocasiones relacionadas con abrasiones o rasguños en la superficie del ojo.

El retraso psicomotor en las cuatro áreas del desarrollo es marcado. El apoyo con estimulación temprana y rehabilitación desde los primeros meses de vida han proporcionado buenos resultados, reflejados en la evolución demostrada a través del test de Denver. Está descrito el retraso mental de grado variable como parte de este síndrome. ${ }^{1-2}$

En relación con la evolución antropométrica, en este caso, se presenta desnutrición crónica y microcefalia; esto podría estar asociado a las complicaciones de este desorden genético o a otros factores sociales y ambientales.

El diagnóstico diferencial entre otras neuropatías hereditarias se basó principalmente en la edad de aparición del cuadro clínico, en la marcada insensibilidad al dolor y en la ausencia de sudoración. Otros datos importantes para tomar en cuenta para el diagnóstico diferencial son la normalidad de respuesta de reflejos tendinosos profundos y el retraso del desarrollo madurativo. La sospecha clínica se ratifica con el resultado de la biopsia de piel.

Las características clínicas encontradas en la paciente son las típicas descritas en esta patología y se contrastan con varios casos que se describen en la literatura. Cabe señalar que un hecho importante fue la relativa detección temprana de esta enfermedad de difícil diagnóstico, lo que ha permitido prevenir o tratar a tiempo varias complicaciones relacionadas.

En ausencia de tratamiento etiológico, la implementación de nuevas estrategias de prevención de acuerdo con el desarrollo y crecimiento de la niña son indispensables. Además, es necesario un abordaje especializado y multidisciplinario para promover un mejor desarrollo, disminuir los riesgos, tratar las complicaciones y secuelas de forma adecuada.

Es fundamental la participación y colaboración de los padres y familiares, los cuales deben ser capacitados continuamente para evitar todos los eventos que suponen un posible riesgo para la paciente. En el caso presentado, la dedicación y el afecto del entorno familiar han sido claves en su evolución favorable.

\section{REFERENCIAS}

1. Vicente-Fatela L, Acedo MS. Trastornos de la reactividad al dolor. Rev Soc Esp Dolor 2004;11(1):31-7.

2. Lee ST, Lee J, Lee M, Kim JW, et al. Clinical and genetic analysis of Korean patients with congenital insensitivity to pain with anhidrosis. Muscle Nerve 2009;40(5):855-9.

3. RosembergS,MarieSK,KilemannS.Congenitalinsensitivity to pain with anhidrosis (hereditary sensory and autonomic neuropathy type IV). Pediatric Neurol 1994;11(1):50-6.

4. Mobini M, Javadzadeh A, Forghanizadeh J. Neuropathic osteroarthropathy in a patient with congenital insensitivity to pain. Arch Iran Med 2009;12(6):599-602.

5. Oliveira CRD, Paris VC, Pereira RA, Lara FST. Anestesia em paciente com insensibilidade congênita a dor e anidrose. Rev Bras Anestesiol 2009;59(5):602-9.

6. DyckPJ.Neuronalatrophyanddegeneration predominantly affecting peripheral sensory and automatic neurons. En: Dyck PJ, Thomas PK, Griffin JW, Low PA, Poduslo JF, eds. Peripheral neuropathy. $3^{\text {rd }}$ ed. Philadelphia: WB Saunders; 1993.Págs.1065-93.

7. Nagasako EM, Oaklander AL, Dworkin RH. Congenital insensitivity to pain: an update. Pain 2003;101(3):213-9.

8. Axelrod FB, Gold-von Simson G, Oddoux C. Hereditary Sensory and Autonomic Neuropathy IV. 2008 Aug 5 [Updated 2009 Nov 24]. En: Pagon RA, Adam MP, Ardinger $\mathrm{HH}$ et al., eds. Gene Reviews ${ }^{\circledR}$ [Internet]. Seattle (WA): University of Washington, Seattle;1993-2014. [Disponible en: http:/ / www.ncbi.nlm.nih.gov/books/NBK1769/]. [Consulta: 14 de abril de 2014].

9. Gao L, Guo H, Ye N, Bai Y, et al. Oral and craniofacial 
manifestations and two novel missense mutations of the NTRK1 gene identified in the patient with congenital insensitivity to pain with anhidrosis. PLoS One 2013;8(6):e66863.

10. Miranda C, Di Virgilio M, Selleri S, Zanotti G, et al. Novel pathogenic mechanism of congenital insensitivity to pain with anhidrosis genetic disorder unveiled by functional analysis of neurotrophic tyrosine receptor kinase type $1 /$ nerve growth factor receptor mutations. J Biol Chem 2002;277(8):6455-62.

11. Colomer-OferilJ. Aspectos clínicos y abordaje diagnóstico y terapéuticodelasneuropatíashereditariassensitivomotoras. Rev Neurol 2002;35(3):239-45. 